\title{
Gonadotrophin-induced abnormalities in sheep oocytes after superovulation
}

\author{
R. M. Moor, J. C. Osborn and I. M. Crosby \\ A.F.R.C. Institute of Animal Physiology, Animal Research Station, 307 Huntingdon Road, \\ Cambridge CB3 OJQ, U.K.
}

\begin{abstract}
Summary. The development of preovulatory follicles involves an initial phase of somatic cell differentiation and a final phase, initiated by the LH surge, when both the somatic and germinal compartments alter. Abnormalities in this pattern of compartmental development after superovulation have been identified by examining follicles from control, PMSG- and FSH-treated sheep. The pattern of proteins synthesized by oocytes from untreated sheep did not differ after culture of follicles in hormone-free medium from that of germinal vesicle oocytes in vivo. Similarly, $93.5 \%$ of oocytes from sheep injected with a pituitary gonadotrophin (FSH-P) synthesized the unchanged germinal vesicle pattern of proteins during culture in an hormonally neutral culture environment. By contrast, the administration of the placental gonadotrophin, PMSG, induced in $28 \%$ of oocytes changes in the pattern of synthesis which are normally associated with maturation. An examination of follicular steroidogenesis showed that both total output and particularly oestrogen secretion was over twice as high in follicles from PMSG-treated as compared with FSH-treated animals $(P<$ $0 \cdot 01)$.

We conclude that the compartmental pattern of development and steroidogenesis is grossly perturbed in many follicles from PMSG-treated animals. Premature activation of the germinal compartment results in aged or abnormal oocytes and a hostile reproductive tract.
\end{abstract}

\section{Introduction}

The development of Graafian follicles during the preovulatory period occurs in two distinct phases. The first phase, which terminates after the preovulatory LH surge, is characterized by the growth, differentiation and development of the somatic components of follicles destined to ovulate. Amongst the most important changes at this time are those relating to cellular morphology, the development and full expression of gonadotrophin receptors, particularly in the membrana granulosa, and the reprogramming and enhancement of steroid synthesis (Richards, 1980; McNatty, 1982). However, these somatic changes are not accompanied by parallel changes in the germinal compartment. Measurements of membrane function, protein synthesis, phosphorylation and ultrastructural appearance all indicate that oocytes in the first phase of development are similar to oocytes from small non-stimulated antral follicles (Masui \& Clarke, 1979). By contrast, during the second phase of development, which occurs after the LH surge, major changes take place in the germinal and somatic compartments of the follicle.

The purpose of our study has been to test whether, and to what extent, the normal sequence of developmental events is altered in follicles stimulated by exogenous gonadotrophins.

\section{Materials and Methods}

Ovaries were obtained from sheep on Day 12-13 of the oestrous cycle (Day 1 = day of oestrus). Animals in the control group were untreated, those in a second group were $_{\text {injected }}$ with 12502 i. $u_{1: 10: 04 \mathrm{PM}}$ 
PMSG (ARS, Cambridge) and slaughtered $40 \mathrm{~h}$ later, and those in the third group were given a total of $10 \mathrm{mg}$ porcine pituitary gonadotrophin (FSH-P: Armour-Baldwin Labs, Omaha, NE, U.S.A.) in three equal doses 48,40 and $24 \mathrm{~h}$ before slaughter. Intact non-atretic follicles (classified according to the criteria of Moor, Hay, Dott \& Cran, 1978) were dissected from the ovaries at room temperature and cultured for $21 \mathrm{~h}$ using the same media and techniques as described previously (Moor \& Trounson, 1977). Some follicles from each of the three groups were cultured with no hormones added to the medium whilst the remainder were cultured in medium containing FSH (NIH-S12, $5 \mu \mathrm{g} / \mathrm{ml}$ ), LH (NIH-S20, $5 \mu \mathrm{g} / \mathrm{ml}$ ) and prolactin (NIH-S9, $20 \mathrm{ng} / \mathrm{ml}$ ) (Moor \& Trounson, 1977).

The cumulus-oocyte complex was removed from each follicle after $21 \mathrm{~h}$ in culture and labelled at $37^{\circ} \mathrm{C}$ for $3 \mathrm{~h}$ in a solution of $500 \mu \mathrm{Ci}\left[{ }^{35} \mathrm{~S}\right]$ methionine $/ \mathrm{ml}$ (sp. act. $1000 \mathrm{Ci} / \mathrm{mmol}$ : Amersham International, Bucks, U.K.). The incubation medium, labelling procedure and electrophoretic separation of polypeptides in individual oocytes were the same as those described previously (Moor, Osborn, Cran \& Walters, 1981).

The progesterone and total unconjugated oestrogen contents of the culture medium were measured using methods and antisera previously described (Moor, Hay, McIntosh \& Caldwell, 1973). The cross-reactivity of the progesterone antiserum (Specific Antisera Ltd, South Bank, Davylands, Wilmslow, Cheshire, U.K.) estimated at $50 \%$ displacement of labelled progesterone was, with the exception of pregnenolone (3.5\%), less than $1 \%$ for all major steroids secreted by the ovine follicle (Seamark, Moor \& McIntosh, 1974). The cross-reactivity of the oestradiol-17 antiserum (donated by Dr B. J. A. Furr, I.C.I.) was $<1 \%$ for the $\mathrm{C}_{19}$ and $\mathrm{C}_{21}$ steroids. The crossreactivity with the $C_{18}$ steroids was $55 \%$ for oestrone, $6 \%$ for oestradiol- $17 \alpha$, and $49 \%$ for oestrone sulphate. The radioimmunoassay for testosterone was validated by Moor (1977). The crossreactivity of testosterone antiserum (Specific Antisera Ltd) was $<0.01 \%$ for $\mathrm{C}_{18}$ steroids, $100 \%$ for $5 \alpha$-dihydrotestosterone, $43 \%$ for $5 \alpha$-androstane- $3 \alpha, 17 \beta$-diol, $41 \%$ for $5 \alpha$-androstane- $3 \alpha, 17 \beta$-diol;

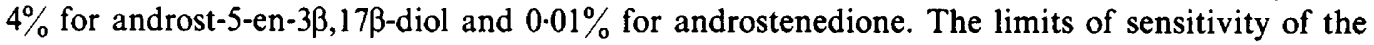
assays were $3 \mathrm{pg}$ oestrogen $/ \mathrm{ml}, 50 \mathrm{pg}$ testosterone $/ \mathrm{ml}$ and $25 \mathrm{pg}$ progesterone $/ \mathrm{ml}$. The within-assay and between-assay coefficients of variation for the assays were, respectively, 6 and $7 \%$ for oestrogen, 5 and $7 \%$ for testosterone and 6.5 and $11 \%$ for progesterone.

Each of the comparative experiments in this study were repeated in consecutive years to check for seasonal variability. Since there were no statistically significant seasonal effects the results have been combined for final presentation.

\section{Results}

\section{Exogenous gonadotrophin and oocyte function}

Oocyte function in untreated sheep. In preliminary experiments, follicles, dissected from the ovaries of untreated sheep, were cultured for $24 \mathrm{~h}$ before the oocytes were removed for nuclear examination. Almost all the oocytes from follicles cultured without hormonal additions contained intact dictyate nuclei at harvest (46 out of 47). By contrast, inclusion of FSH and LH in the culture medium induced germinal vesicle breakdown in 30 out of 39 oocytes $(79 \%)$. These observations demonstrate, in accord with results of earlier studies (Moor \& Trounson, 1977), that over 95\% of oocytes in follicles from unstimulated animals remain in the germinal vesicle state (GV) when cultured for $24 \mathrm{~h}$ in medium devoid of FSH and LH. This conclusion was verified by examining the pattern of proteins synthesized by such oocytes. Protein synthesis by oocytes from unstimulated follicles after culture was indistinguishable from that produced by oocytes taken directly from follicles in vivo (Warnes, Moor \& Johnson, 1977). Since culture does not itself induce morphological or biochemical changes in oocytes maintained within unstimulated follicles, in the subsequent experiments intrafollicular oocytes from unstimulated sheep served as controls against which oocytes from hormone-treated animals were compared. 

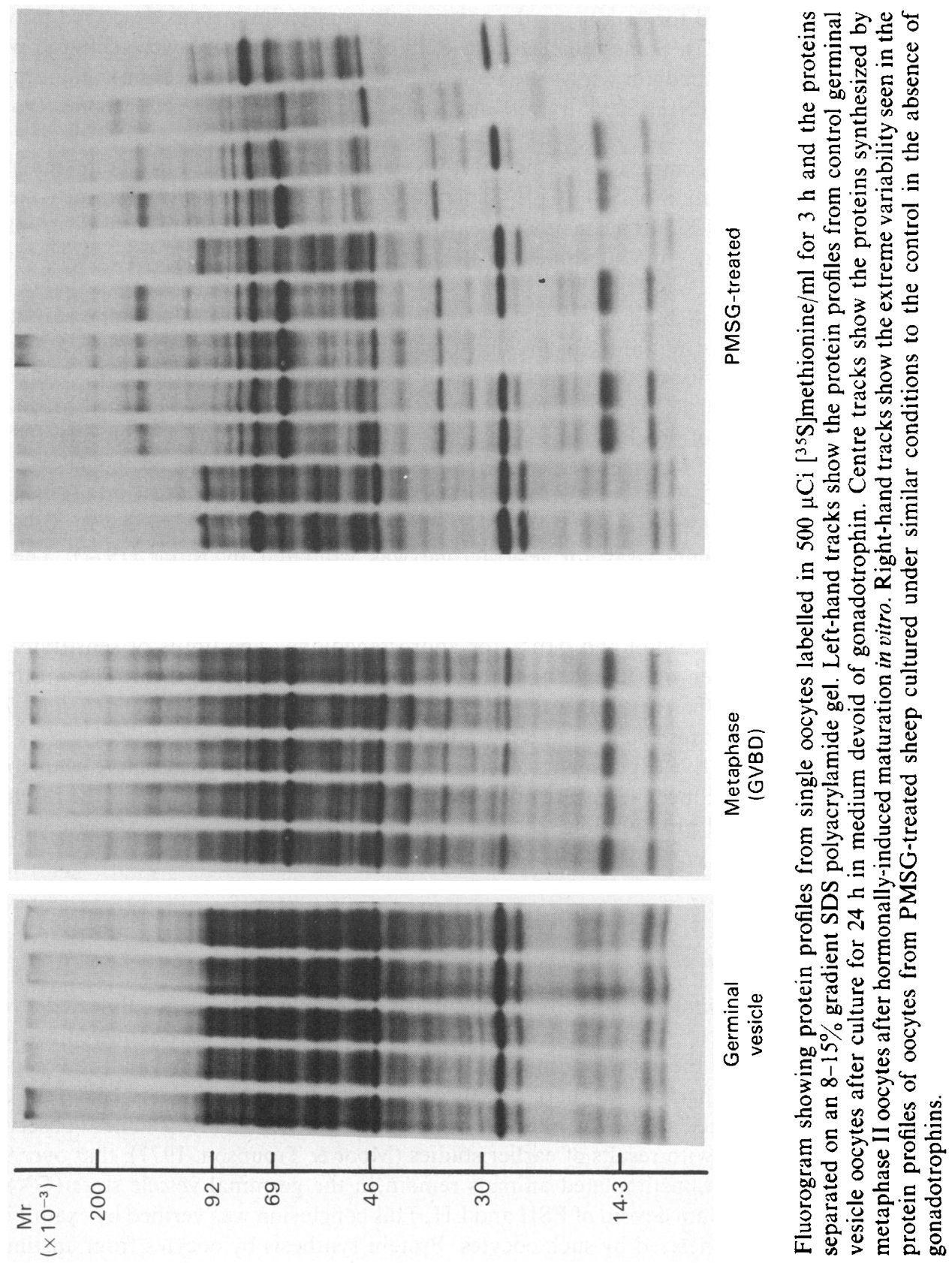
Table 1. Analysis of the patterns of protein synthesis in sheep oocytes exposed to different combinations of gonadotrophins in vivo and in vitro

\begin{tabular}{|c|c|c|c|c|}
\hline \multirow{2}{*}{$\begin{array}{l}\text { Treatment } \\
\text { in vivo }\end{array}$} & \multirow{2}{*}{$\begin{array}{l}\text { Treatment } \\
\text { in vitro }\end{array}$} & \multirow[b]{2}{*}{ Total } & \multicolumn{2}{|c|}{ No. of oocytes } \\
\hline & & & Unchanged & Changed $(\%)$ \\
\hline - & - & 22 & 21 & $1(4 \cdot 5)$ \\
\hline - & FSH-LH & 22 & 7 & $15(68 \cdot 2)$ \\
\hline FSH-P & - & 115 & 108 & $7(6 \cdot 5)$ \\
\hline FSH-P & FSH-LH & 145 & 44 & $101(69 \cdot 7)$ \\
\hline PMSG & - & 101 & 73 & $28(27 \cdot 7)$ \\
\hline PMSG & FSH-LH & 28 & 9 & $19(67.9)$ \\
\hline
\end{tabular}

Oocyte function after FSH-P injection. All the non-atretic follicles $>2 \mathrm{~mm}$ in diameter were dissected from the ovaries of sheep $24 \mathrm{~h}$ after the final injection of FSH-P and 115 of these follicles were cultured for $24 \mathrm{~h}$ in medium devoid of hormones. Protein synthesis in $93.5 \%$ of the oocytes was identical to that from unstimulated sheep (Table 1). It is, therefore, clear that FSH-P administration in vivo does not induce premature protein synthetic changes in oocytes from this type of stimulated follicle. That the oocytes from these follicles were, however, fully responsive to appropriate gonadotrophin stimulation was demonstrated by adding FSH and LH to the culture medium. An analysis of the protein patterns of oocytes from 145 follicles exposed to hormones in culture showed that $70 \%$ had undergone full reprogramming of protein synthesis and were synthesizing proteins characteristic of normal oocytes at metaphase II. We interpret these results as indicating that exogenous FSH mimics the action of the endogenous hormone by acting directly on the somatic but not on the germinal compartment of antral follicles.

Oocyte function after PMSG injection. A total of 101 non-atretic follicles $>2 \mathrm{~mm}$ in diameter dissected from the ovaries of PMSG-treated sheep were cultured in the absence of additional hormones (Table 1). Protein patterns from the oocytes of these follicles were in marked contrast to those from control or FSH-P-treated sheep with $27.7 \%$ of the oocytes exhibiting major changes in protein synthesis characteristic of maturation. Plate 1 shows an example of the extreme variability in protein synthesis in oocytes from certain PMSG-treated animals. Almost the same proportion of oocytes from PMSG-treated sheep underwent characteristic maturational changes after FSH and LH treatment in culture as occurred in the control and FSH-P groups. However, $27 \%$ of the reprogrammed oocytes from the PMSG-treated sheep group were probably already activated before the addition of the hormones to the culture medium.

\section{Steroid synthesis in gonadotrophin-treated sheep}

Steroid secretion by cultured follicles is shown in Table 2 . The presentation of the results as ng steroid per $\mathrm{mg}$ follicular tissue $/ 24 \mathrm{~h}$ provides a basis for the measurement of hormonal action on the efficiency with which follicles synthesize steroids. Two clear conclusions can be reached by comparing steroid secretion in follicles obtained from sheep superovulated with FSH-P or PMSG. The first is that the method of superovulation affects both the amount and pattern of secreted steroids. When follicles were cultured in a gonadotrophin-free environment, those from FSH-Ptreated sheep secreted steroids in a pattern that closely resembled that secreted by the preovulatory follicle obtained before the LH surge (Seamark et al., 1974). By contrast, follicles from PMSGtreated sheep cultured without gonadotrophins produced significantly more total steroid (79 compared with $38 \mathrm{ng} / \mathrm{mg}$ per $24 \mathrm{~h}: P<0.01, t$ test) and in a pattern different from that of the FSH$P$ group. The second difference between follicles from the two groups is reflected by their response to the addition of FSH and LH in culture. The addition of gonadotrophins to follicles from FSH-Ptreated sheep increased significantly $(P<0.05, t$ test $)$ the total output of steroid but did not alter the 
Table 2. Steroid secretion (ng/mg follicular tissue per $24 \mathrm{~h}$ ) by sheep follicles exposed to different combinations of gonadotrophins in vivo and in vitro

\begin{tabular}{lccccc}
\hline & & & \multicolumn{3}{c}{ Steroid secreted } \\
\cline { 4 - 6 } $\begin{array}{c}\text { Treatment } \\
\text { in vivo }\end{array}$ & $\begin{array}{c}\text { Treatment } \\
\text { in vitro }\end{array}$ & $\begin{array}{c}\text { No. of } \\
\text { follicles }\end{array}$ & Oestrogen & Testosterone & Progesterone \\
\hline FSH-P & - & 45 & $22 \pm 3$ & $16 \pm 3$ & 0 \\
FSH-P & FSH-LH & 81 & $43 \pm 5$ & $20 \pm 3$ & $9 \pm 1$ \\
PMSG & - & 34 & $63 \pm 6$ & $14 \pm 3$ & $2 \pm 1$ \\
PMSG & FSH-LH & 43 & $64 \pm 9$ & $37 \pm 5$ & $10 \pm 3$ \\
\hline
\end{tabular}

Values are mean \pm s.e.m.

relative proportions of the three steroids from that produced by similar follicles in hormone-free medium. By contrast, addition of FSH and LH to follicles in the PMSG group not only increased total steroid output but also markedly altered the pattern of steroids produced. The gonadotrophins induced significant increases in testosterone and progesterone output without any accompanying change in oestrogen synthesis.

\section{Discussion}

The underlying purpose of this study was to ascertain whether the development of follicles and oocytes after gonadotrophin therapy deviated from that of preovulatory follicles in the normal ovarian cycle. The experiments centred around the extent and timing of differentiation in both the somatic and germinal tissues of the follicle and in particular on the differential action of gonadotrophins on these two cellular compartments. The work was undertaken because it was anticipated that the results would have relevance to the induction of multiple ovulations in women and domestic animals and to the validity of using PMSG-primed laboratory rodents as a source of follicles and oocytes for subsequent experimental study.

The experimental approach was based on the premise that early or subtle changes induced in follicles by exogenous gonadotrophins would, with time, manifest themselves in a neutral culture environment. Support for this assumption came initially from experiments which showed that follicular differentiation, once initiated, proceeds accurately for many days in culture (Moor et al., 1973). The 'in-vivo-in-vitro' approach has more recently been used with notable success in the study of follicular receptor development (Richards, 1980). Our present results demonstrate further the value of this model in the study of follicular differentiation. However, our experiments differ from the earlier ones primarily because we have concentrated on the action of gonadotrophins on the germinal rather than the somatic compartment of the follicle. Moreover, we have measured protein changes in oocytes rather than other characteristics because these are the most sensitive indicators of change in this cell type that are presently available.

The main conclusions from these experiments are clear and relate to both compartments of the ovary. Firstly, our results show that the germinal compartment in follicles from untreated or FSH-P treated animals remains selectively unchanged until exposed to an adequate 'surge' level of FSH and LH in culture. By contrast, not only the somatic but also the germinal compartment undergoes change in $25-30 \%$ of follicles as a result of PMSG stimulation in vivo. However, this proportion of prematurely activated oocytes depends on the amount of gonadotrophin administered. The amounts of FSH-P and PMSG used in the present study are those routinely used for superovulation of sheep and result in an ovulation rate in our flock of about 8-10 ovulations per animal. Because of its short half-life in vivo (see below), FSH-P was administered in three equal doses (48, 40 and $24 \mathrm{~h}$ before slaughter) to generate a prolonged stimulation of follicle development similar to that produced by the single injection of PMSG. Preliminary experiments have shown that, if the dose of PMSG is reduced by $40 \%$, both the number of ovulations and the proportion of prematurely 
activated eggs are greatly decreased. Likewise, if the FSH-P dose is increased by $40 \%$ up to a fifth of oocytes from these animals show clear evidence of premature activation. The second series of conclusions concern the effect of exogenous hormones on the somatic compartment of follicles. The findings suggest that FSH-P increases the size of follicles but neither increases their steroidogenic efficiency (expressed as ng steroid per mg tissue) nor alters the pattern of steroids as compared with that produced by follicles from untreated sheep. On the other hand, PMSG administration increases not only follicle size but also steroidogenic efficiency; it also alters the pattern of steroids secreted.

The explanation for the differences in hormonal action on the follicle can almost certainly be attributed to the chemical properties of the two gonadotrophic preparations. The pituitary preparation (FSH-P) consists of a mixture of FSH and LH molecules in a ratio which varies from about 0.3 to 1.0 (Chupin, Combarnous \& Procureur, 1984; Murphy, Mapletoft, Manns \& Humphrey, 1984). A further distinguishing feature of the pituitary gonadotrophins is their low sialic acid content and associated short half life in vivo (Gay, Midgley \& Niswender, 1970). By contrast, the placental gonadotrophin, PMSG, is endowed with an exceptionally high sialic acid content, a consequent long half-life and a predominant LH-like activity when measured by bioassay (Shams, Menzer, Schallenberger, Hoffman \& Hahn, 1978). The slow clearance rate of PMSG coupled with its dominant LH-like activity in vivo provide a ready explanation for the premature activation of oocytes, especially in those follicles that show the greatest degree of receptor differentiation at the time of hormone injection.

These experiments are of practical relevance for a number of different reasons. They demonstrate that exogenous gonadotrophins, administered at high levels or using inappropriate types, will grossly disturb the biochemical function of the oocyte. This premature activation of oocytes causes abnormalities both because the follicular environment is likely to be unsuitable for maturation at this early stage and because the oocyte will already be aged at ovulation. The very high levels of FSH used in certain clinical procedures might well induce premature activation in a number of oocytes. The problem of 'over-ripe' oocytes has generally not been sufficiently recognized as a potential major source of embryonic loss. That superovulation is a problem that results in many abnormal embryos is universally recognized in animal breeding (see Gordon, 1982). One of the difficulties is the variability in the dynamics of the follicular populations in different females and therefore cannot be readily overcome (Monniaux, Chupin \& Saumande, 1983). Our results showing that PMSG is more liable than FSH to disrupt the normal function of the oocyte accord well with findings indicating that PMSG decreases fertilization rate in the rat and increases embryonic loss at the preimplantation stage of development (Miller \& Armstrong, 1981; Evans \& Armstrong, 1983). It is probable that the current trend of using pituitary rather than placental gonadotrophins for superovulation will accelerate. Improvement and standardization of the pituitary gonadotrophin and also in its mode of administration should further increase the number and viability of embryos produced by superovulation.

One of the most widely used methods of obtaining follicles and oocytes for experimental study involves injecting immature females with PMSG and removing the ovaries $24-48 \mathrm{~h}$ later. The oocytes from such ovaries are used in many studies on maturation despite reports showing lowered fertilization rates and increased preimplantation losses associated with these procedures (Miller \& Armstrong, 1981; Evans \& Armstrong, 1983). The cause of the embryonic abnormalities has previously been ascribed to the elevated levels of circulating steroid in PMSG-treated animals (Booth, Newcomb, Strange, Rowson \& Sacher, 1975). Our results confirm that PMSG causes excessive follicular steroid secretion but also focusses attention on the adverse effects of this gonadotrophin on the maturing oocyte. It would be prudent to take account of these unacceptable features of PMSG both in planning future experiments and in interpreting past results.

The partly purified gonadotrophins used in this study were generously donated by the National Institutes of Arthritis, Metabolism and Digestive Diseases, National Institutes of Health, 
Bethesda, MD. The PMSG was kindly prepared and standardized by Colin Brown. J.C.O. is indebted to the Medical Research Council for financial support.

\section{References}

Booth, W.D., Newcomb, R., Strange, H., Rowson, L.E.A. \& Sacher, H.B. (1975) Plasma oestrogen and progesterone in relation to superovulation and egg recovery in the cow. Vet. Rec. 97, 366-369.

Chupin, D., Combarmous, Y. \& Procureur, R. (1984) Antagonistic effect of LH on FSH-induced superovulation in cattle. Theriogenology 21, 229.

Evans, G. \& Armstrong, D. T. (1983) Reduction in fertilization rate in vitro of ocytes from immature rats induced to superovulate. J. Reprod. Fert. 70, 131135.

Gay, V.L., Midgley, A.R. \& Niswender, G.D. (1970) Patterns of gonadotrophic secretion associated with ovulation. Fedn Proc. Fedn Am. Soc. exp. Biol. 29, 1880-1887.

Gordon, I. (1982) Synchronization of oestrus and superovulation in cattle. In Mammalian Egg Transfer, pp. 63-80. Ed. C. E. Adams. CRC Press, Boca Raton.

Masui, Y. \& Clarke, H.J. (1979) Oocyte maturation. Int. Rev. Cytol. 57, 186-282.

MeNatty, K.P. (1982) Ovarian follicular development from the onset of luteal regression in humans and sheep. In Follicular Maturation and Ovulation, pp. 118. Eds R. Rolland, E. V. van Hall, S. G. Hillier, K. P. McNatty \& J. Shoemaker. Excerpta Medica, Amsterdam.

Miller, B.G. \& Armstrong, D.T. (1981) Effects of a superovulatory dose of pregnant mare serum gonadotrophin on ovarian function, serum estradiol, and progesterone levels and early embryo development in immature rats. Biol. Reprod. 25, 261-271.

Monniaux, D., Chupin, D. \& Saumande, J. (1983) Superovulatory response of cattle. Theriogenology 19, 55-81.

Moor, R.M. (1977) Sites of steroid production in ovine Graafian follicles in culture. J. Endocr. 73, 143-150.

Moor, R.M. \& Trounson, A.O. (1977) Hormonal and follicular factors affecting maturation of sheep oocytes in vitro and their subsequent developmental capacity. J. Reprod. Fert. 49, 101-109.
Moor, R.M., Hay, M.F., MeIntosh, J.E.A. \& Caldwell, B.V. (1973) Effect of gonadotrophins on the production of steroids by sheep ovarian follicles cultured in vitro. J. Endocr. 58, 599-611.

Moor, R.M., Hay, M.F., Dott, H.M. \& Cran, D.G. (1978) Macroscopic identification and steroidogenic function of atretic follicles in sheep. J. Endocr. 77, 309318.

Moor, R.M., Osborn, J.C., Cran, D.G. \& Walters, D.E. (1981) Selective effect of gonadotrophins on cell coupling, nuclear maturation and protein synthesis in mammalian oocytes. J. Embryol. exp. Morph. 61, 347365.

Murphy, B.D., Mapletoft, R.J., Manns, J. \& Humphrey, W.D. (1984) Variability in gonadotrophin preparations as a factor in the superovulation response. Theriogenology 21, 117-125.

Richards, J.S. (1980) Maturation of ovarian follicles: actions and interactions of pituitary and ovarian hormones on follicular cell differentiation. Physiol. Rev. 60, 51-89.

Schams, D., Menzer, Ch., Schallenberger, E., Hofiman, B. \& Hahn, R. (1978) Some studies on pregnant mare serum gonadotrophin (PMSG) and on endocrine responses after application for superovulation in cattle. In Control of Reproduction in the Cow, pp. 122143, Ed. J. M. Sreenan. Martinus Nijhoff, The Hague.

Seamark, R.F., Moor, R.M. \& McIntosh, J.E.A. (1974) Steroid hormone production by sheep ovarian follicles cultured in vitro. J. Reprod. Fert. 41, 143-148.

Warnes, G.M., Moor, R.M. \& Johnson, M.H. (1977) Changes in protein synthesis during maturation of sheep oocytes in vivo and in vitro. J. Reprod. Fert. 49, $331-335$. 